\title{
BMJ Open Trends in suicidal behaviour in Dutch general practice 1983-2013: a retrospective observational study
}

\author{
Derek P de Beurs, ${ }^{1}$ Mariette Hooiveld, ${ }^{1}$ Ad J F M Kerkhof, ${ }^{2}$ Joke C Korevaar, ${ }^{1}$ \\ Gé A Donker ${ }^{1}$
}

To cite: de Beurs DP, Hooiveld M, Kerkhof AJFM, et al. Trends in suicidal behaviour in Dutch general practice 1983-2013: a retrospective observational study. BMJ Open 2016;6: e010868. doi:10.1136/ bmjopen-2015-010868

- Prepublication history for this paper is available online To view these files please visit the journal online (http://dx.doi.org/10.1136/ bmjopen-2015-010868)

Received 15 December 2015 Revised 29 February 2016 Accepted 2 March 2016

CrossMark

\begin{abstract}
${ }^{1}$ Netherlands Institute for Health Services Research (NIVEL, Utrecht, The Netherlands

${ }^{2}$ Department of Clinical Psychology, VU Amsterdam, Amsterdam, The Netherlands
\end{abstract}

Correspondence to Dr Derek de Beurs; derekdebeurs@gmail.com

\section{ABSTRACT}

Objectives: To analyse trends in suicidal behaviour as reported by the Dutch sentinel general practices from 1983 to 2013. Second, to examine the relationship between suicidal behaviour and several patient characteristics. Finally, to compare the relationship between suicidal behaviour and patient characteristics before (1983-2007) and after (2008-2013) the start of the crisis.

Setting: 40 general practices in the Netherlands during the period 1983-2013.

Participants: Patients with an ICPC code of P77 (suicide attempt).

Primary and secondary outcomes: Primary outcomes were age-adjusted and gender-specific trends in reported suicides (342) and suicide attempts (1614). Secondary outcomes were the relationship between suicidal behaviour and age, household composition, history of depression, recognition of suicide ideation, treatment before the suicidal behaviour and contact within the past month before suicidal behaviour for the period 1983-2013. Additionally, separate frequencies for the periods 1983-2007 and 2008-2013 were presented.

Results: Join-point analyses revealed a significant rise in male suicides from 2008 ( $b=0.32, S E=0.1$, $p=0.008)$, and an increase in male suicide attempts since $2009(b=0.19, S E=0.04, p<0.001)$. Female suicidal behaviour showed a steady decrease from 1989 to 2013(b=-0.03, SE=0.007, $p<0.0001$ for female suicide, $b=-0.02, S E=0.002, p<0.001$ for female attempts). Before 2007, a history of depression was reported in $65 \%(168 / 257)$ of the suicides. After the start of the recession, a depression was recognised in $44 \%(22 / 50)$ of the patients who died by suicide.

Conclusions: Since 2008, there was a rise in the male suicide rate while female suicide behaviour has continued to decline. General practitioners less often reported a history of depression within patients who died due to suicide after 2007 than before. Training in the early recognition of suicide ideation in depressive patients might improve suicide prevention in primary care.

\section{INTRODUCTION}

The general practitioner (GP) plays an important role in suicide prevention.

\section{Strengths and limitations of this study}

- First study on trends of suicidal behaviour in Dutch primary care in the years 1983-2013.

- First study on suicide rates in primary care using join point regression modelling.

- General practitioners (GPS) collected additional information on patient characteristics of suicidal patients.

- GPs answered questions on suicidal behaviour retrospectively, possibly resulting in a recall bias.

- Under-reporting of suicidal behaviour may have occurred.

In many countries, the GP is the first accessible contact for patients with mental health problems, making them important gatekeepers to identify suicidal ideation at an early stage. ${ }^{1}$ The integrated motivational volitional model (IVM) argues that patients gradually move from suicidal thoughts (the motivational phase) to actual suicidal behaviour (the volitional phase). ${ }^{2}$ Early identification of suicidal thoughts within general practice can prevent the patient from going further in the suicidal process, and prevent the patient moving from suicidal thoughts to suicidal actions. In Germany, a multifaceted programme that improved the attitude and skills of GPs towards recognition and treatment of depressed and suicidal patients via workshops and other educational interventions resulted in a sustained decline in suicidal behaviour of $32.4 \%$ in the 3 years after the start of the intervention. ${ }^{34}$

A review found that, on average, $45 \%$ of the suicidal patients had been in contact with their GP in the 30 days period before the suicidal event. ${ }^{5}$ However, NIVEL data also showed that risk for suicide was only identified in $31 \%$ of the cases, indicating that the early timely recognition of suicidal behaviour is difficult within primary practice. ${ }^{6}$

In the Dutch healthcare system, most of the non-institutionalised citizens are enlisted 
as patients in a practice and the GP acts as a gatekeeper to secondary care. ${ }^{7}$ For mild psychological problems, the GP, supported by a mental health nurse, can offer antidepressants and different forms of psychological counselling. Patients with more severe psychiatric symptoms or an actual psychiatric disorder are referred to specialised mental healthcare. ${ }^{7}$ The availability and accessibility of GPs give them an important preventive function for suicidal behaviour. This is different, for example, in Belgium, where patients are free to consult any care provider, and GPs were found to be moving back from the first line of care for suicidal patients. ${ }^{8}$ Also, compared to patients in the Netherlands, patients in Belgium feel there is more stigma associated with consulting their GP for psychological problems. ${ }^{9}$

From 2007 to 2013, Dutch suicide rates have risen by $5 \%$ each year, from 1353 suicides in 2007 to 1854 in $2013{ }^{10}$ The average suicide rate increased from 10 to $11 / 100000$. Although this is often attributed to the rise in unemployment, the unemployment rates in the Netherlands only started going up in $2009 .^{10}$ The start of an economic recession typically results in more people feeling entrapped, via (the anticipation of) lay-offs, financial problems and increased hopelessness about the future. The IVM model of suicidal behaviour and the recent Dutch multidisciplinary guideline on the assessment and treatment of suicidal behaviour give entrapment a central role in the transition from suicidal thoughts to actual suicidal behaviour. ${ }^{2}{ }^{11}$ Also, during a recession, more people may feel defeated, that they have failed in life and that they have become a burden on others. Defeat, failure and perceived burdensomeness are additional crucial elements for suicidal behaviour in the IVM and the interpersonal psychological theory of suicidal behaviour. ${ }^{2} 12$

In the Netherlands, suicides and attempted suicides are registered by general sentinel practices participating in the NIVEL Primary Care Database. ${ }^{13}$ After reporting a suicide or a suicide attempt, GPs fill in additional questionnaires on the demographics, history of depression and characteristics of care provision such as the last consultation with the GP of the suicidal patient. The last analysis of suicidal behaviour within the NIVEL Primary Care Database was done for the period $1983-2003 .{ }^{7}$ In the current study, we analysed trends in the incidence of suicides and suicide attempts logged in the NIVEL Primary Care Database during 1983-2013. Using joinmodel analysis, we determined whether the incidence started rising, remained stable or declined over a period of 30 years. Similar to other studies we expected a rise in incidence of suicidal behaviour in response to the global recession which started in 2007. ${ }^{14-16}$ Since several studies found no relation between a financial crisis and female suicidal behaviour, ${ }^{16-19}$ we expected no significant change for females. The relationship between patient characteristics such as history of depression and suicidal behaviour will be analysed for the period 19832013. To offer insights into changes of patient characteristics of suicidal patients after the recession, we will also present descriptives of patient characteristics and suicidal behaviour separate for the period before and after the recession.

\section{METHODS}

Cases of suicide or attempted suicide were registered by sentinel general practices participating in the NIVEL Primary Care Database. ${ }^{13}$ Since 1970, the Dutch Sentinel Practices have consisted of about 40 general practices with a practice population covering about $0.8 \%$ of the Dutch population. The practices are nationally representative by age, gender, geographic distribution and population density.

The participating GPs report weekly about certain illnesses, events and procedures in general practice that cannot be collected from routinely registered data. Since 1979, concerning suicides and attempted suicide cases in patients aged 15 years or older, the GP fills out an additional questionnaire addressing the following patient characteristics: age, gender, household composition, history of depression, recognition of suicide ideation, treatment before the suicidal behaviour and contact within the last month before suicidal behaviour. Registration included suicides and attempted suicides among all registered patients, including when the patient was seen by another GP on duty, was treated at an emergency ward, or when hospitalised, although under-reporting may have occurred in these cases. We used the data from the period 1983-2013.

\section{Statistical analysis \\ Primary outcomes}

To estimate national incidence rates, we applied direct age standardisation, taking the age distribution of the Dutch population in 2011 as the standard..$^{20}$ An adjustment factor was applied when estimating incidence rates for incomplete years. We calculated the 3-year moving average to smooth out short-term fluctuations and to be able to highlight longer term trends.

To analyse changes in trends of reported suicides and suicide attempts, we applied join point regression models, ${ }^{21}$ using the Surveillance Epidemiology and End Results statistical software (Joinpoint Regression Program. Version 4.2.0 version: National Cancer Institute, 2015). The software takes trend data (in our case, the age-adjusted 3-year moving average of suicides or suicide attempts) and fits them to the simplest joinmodel that the data allow. The programme tests the null hypotheses of no join point with the alternative of one or more join points. Owing to the well-established differences in suicidal behaviour between men and women, ${ }^{22}$ we stratify trend analyses by gender.

\section{Secondary outcomes}

Using descriptive statistics, we described the number of suicides and suicide attempts in relation to the following 
patient characteristics: age, gender, household composition, history of depression, recognition of suicide ideation, treatment before the suicidal behaviour and contact within the last month before suicidal behaviour. We restricted the analyses to reported suicide (attempts) to the first report for the individual in order to exclude influences of the results by a limited number of persons with (many) repeated suicide attempts. The relation between patient characteristics and suicidal behaviour is presented as a percentage. For example, when we are interested in the percentage of male suicides, we will divide the number of male suicides by the total number of suicides. To indicate the number of participants with missing data, we will present the number of actual cases (n) with the total available sample data $(\mathrm{N})$ for each variable of interest.

To examine changes in characteristics of suicidal behaviour before and after the recession, we compared the frequency of patient characteristics from 1983 to 2017 and from 2008 to 2013. Since the actual number of events of suicidal behaviour in the period after the recession will be relatively low, we will not test for significance but only describe the data.

\section{RESULTS}

\section{Suicide and attempted suicide from 1983 until 2013}

From 1983 to 2013, data were collected on 1956 patients with fatal or non-fatal suicidal behaviour. Three hundred and forty two patients died due to suicide (229 males, 112 females), and there were 1614 reported suicide attempts (561 males, 1041 females). In figure 1, the 3 years moving averages for the number of suicide attempts and suicides are presented by gender.

\section{Trend analysis}

Suicide and gender

Male suicides

When analysing the incidence of male suicides, two significant trend changes join points are observed, one in 1994 and one in 2007 (figure 2). After a significant decrease from 1983 to $1994 \quad(b=-0.06, \quad S E=0.03$, $\mathrm{p}<0.001)$, the trend stabilised from 1994 to 2003 $(\mathrm{b}=0.00, \mathrm{SE}=0.02, \mathrm{p}=0.8)$. Next, there was a decline, although not significantly, in the period 2003-2007 ( $b=$ $-0.16, \mathrm{SE}=0.1, \mathrm{p}=0.1$ ). From 2007 to 2013 , there was a sudden significant increase $(\mathrm{b}=0.32, \mathrm{SE}=0.1, \mathrm{p}=0.008)$.

\section{Male attempts}

Compared to male suicides, we find a similar decline in male attempts from 1983 to $1991 \quad(b=-0.05, S E=0.01$, $\mathrm{p}<0.001)$. From 1991 until 1997, we find a significant rise in incidence $(b=0.1, S E=0.02, p<0.001)$. From 1997 until 2009, there was a decline in incidence, in which the period from 1997 to 2001 was significant $(b=-0.2$, $\mathrm{SE}=0.06, \mathrm{p}=0.004)$. Starting from 2009, there is a significant increase $(b=0.19, \mathrm{SE}=0.04, \mathrm{p}<0.001)$.

\section{Female suicides}

Since 1989, there has been a significant decrease in the incidence of female suicides. $(b=-0.03, \quad S E=0.007$, $\mathrm{p}<0.0001$ ) (figure 3 ). Figure 3 does show a nonsignificant rise in female suicides in 2012-2013.

\section{Female attempts}

Regarding female attempts, the data showed a constant significant decline over the period 1989-2013 $(b=-0.02$, $\mathrm{SE}=0.002, \mathrm{p}<0.001)$.

\section{Patient characteristics and suicidal behaviour: 1983-2013}

Forty eight per cent $(166 / 340)$ of the suicides and $68 \%$ $(1098 / 1603)$ of the suicide attempts took place in the age group of 20-50 years. The peak of male suicides and attempts was around the age of 30-39 (table 1). Female suicides peaked at 40-49 while female attempts peaked between 20 and 29 .

Of the patients who died due to suicide, GPs recalled a history of depression in $63 \%(194 / 308)$ of the cases (57\% for males, $74 \%$ for females), compared to $58 \%$ (871/1503) of the suicide attempts (49\% for males, $63 \%$ for females). Suicide ideation was recalled to be an important feature of the depression of $13 \%$ of the suicidal patients $(116 / 923)$. GPs indicated that $57 \%$ of patients $(1039 / 1825)(53 \%$ men, $60 \%$ female) who later
Figure 1 Age adjusted 3 years moving average for the number of suicide attempts and suicides, stratified by gender.

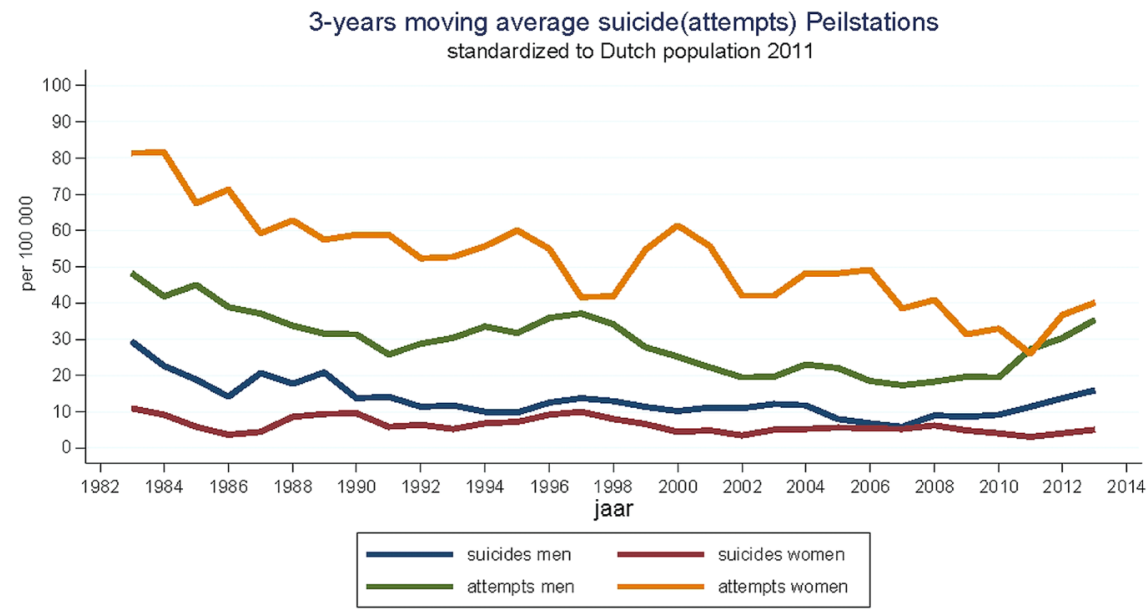




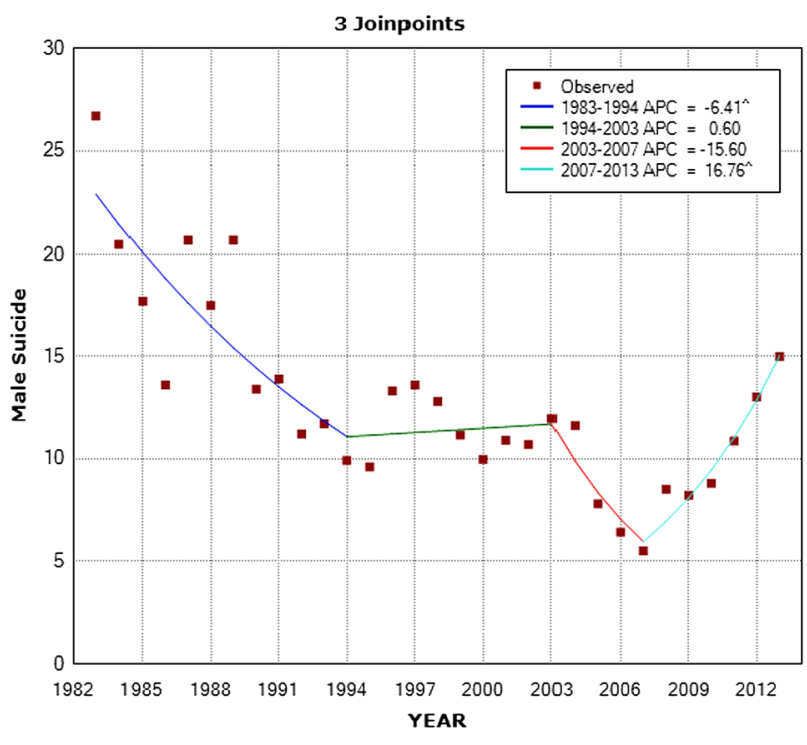

Figure 2 Join point regression analysis of suicide incidence among men 1983-2013.

would engage in fatal or non-fatal suicidal behaviour had been receiving treatment by a specialised mental health professional. Almost half of the suicidal patients $(48 \%(902 / 1878))$ were in contact with a GP within 30 days before the event. In hindsight, GPs stated that suicidal behaviour was a reason for concern during the consultation in $31 \%(54 / 175)$ of the cases who died due to suicide and in $29 \%(185 / 834)$ of the patients who showed non-fatal behaviour within the next 30 days. Forty three per cent $(147 / 340)$ of the patients who died due to suicide lived alone (42\% (95/228) for men, $46 \%$ $(51 / 111)$ for women. Suicide attempters lived alone in $30.3 \%(486 / 1604)$ of the cases $(36 \%(203 / 558)$ for men, $27 \%$ (275/1034) for women).

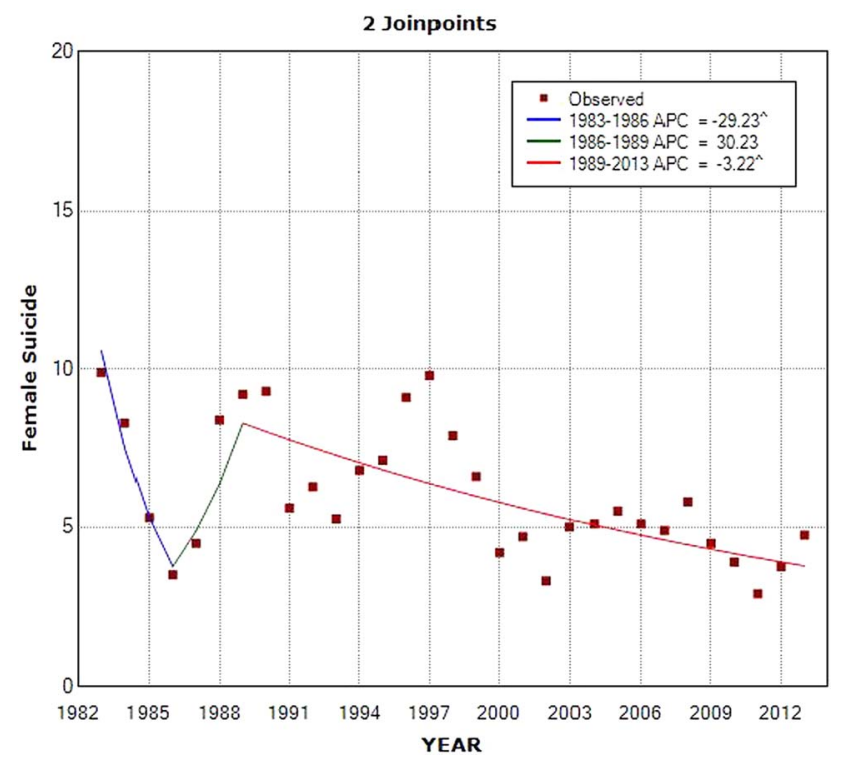

Figure 3 Join point regression analysis of suicide incidence among women 1983-2013.

\section{Suicidal behaviour after 2007}

Compared to the period before 2007, the peak of male suicides shifted from the age group of 30-39 years to the age group of 60-69 years in the period 2008-2013 (table 1). The median age peak of female suicides shifted from 30-39 to 50-59 after the start of the crisis. The median age of suicide attempt for males rose from 30-39 to 40-49. For female suicide attempts, the median age changed from 20-29 to 50-59. Recognition of a history of depression of male patients who died by suicide decreased from $60 \%(102 / 171)$ to $46 \%(16 / 35)$. For females, it decreased from $47 \%(45 / 96)$ to $40 \%$ (9/ $15)$. The number of male suicidal patients who had been treated before the suicide remained stable $(52 \%$, 99/182) after 2007 but decreased for females (table 1).

\section{DISCUSSION}

Since 2008, there has been a rise in the male suicide rate while female suicide behaviour kept on declining. The rate of male suicide attempts started rising since 2009. The trend found in our study is consistent with national trends in suicidal behaviour. ${ }^{10}$ Similar to the national data, the rise was mainly explained by an increase in male fatal suicidal behaviour around the age of 60-69. As is often argued, the rise in middle-aged and older-aged male suicidal behaviour might be explained by the economic recession, during which this group was more at risk of losing their job or remaining unemployed. ${ }^{23}$ Losing one's job, long-term unemployment, or being incapable of work due to long-term illness or handicap influences well-known risk factors for suicidal behaviour, such as hopelessness, feelings of defeat, entrapment and lack of future perspective. ${ }^{15}{ }^{24-27}$ Several authors ${ }^{28}{ }^{29}$ question the relationship between unemployment and suicide because of other pre-existing potential confounders such as a history of mental illness. However, a meta-analysis ${ }^{23}$ demonstrated that unemployment is indeed associated with greater risk of suicide after adjusting for prior mental disorder. Importantly, a recent article showed that a higher suicide rate preceded a rise in unemployment. ${ }^{17}$ The authors hypothesise that males more often die due to suicide in response to the anticipated stress of possible unemployment. This might also explain why, in our study, a history of depression was less often reported among males who died by suicide after the recession. The suicide act might have been more impulsive, as a result of intense feeling of entrapment, without any earlier overt signs of depression.

We found no significant change in female suicidal behaviour. This is in line with many other studies that indicate no relation between unemployment or occupational instability and female suicidal behaviour. ${ }^{16} 181930$ However, we did find that, after the recession, the peak of female suicidal behaviour shifted from the age group of 20-29 years to the age group of 40-59 years. Also, depression was less often recognised for females who 


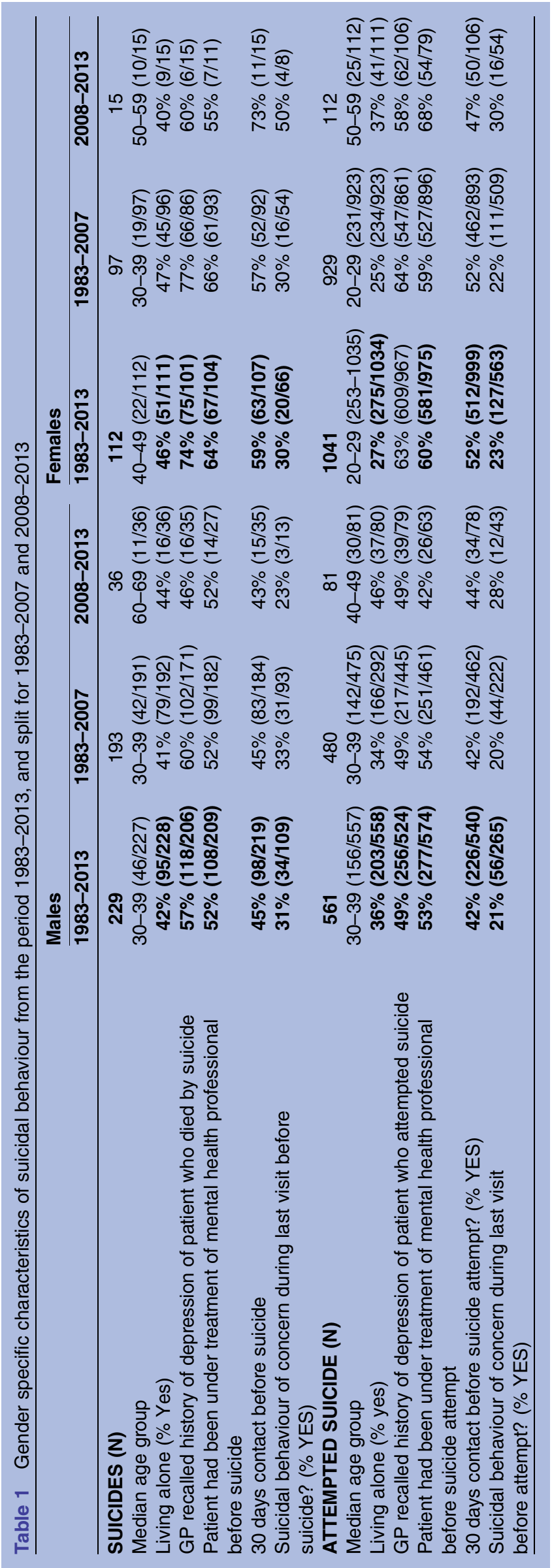

died of suicide after 2007. This indicates that although there is no overall rise in suicidal behaviour among females after the recession, suicidal behaviour among the middle-aged women seems to have increased. Comparable to male suicidal patients, after the crisis the GP less often recognised a history of depression, perhaps indicating more impulsive suicidal behaviour among middle-aged females as well.

Finally, we did observe a non-significant increase in female suicides from 2010, but follow-up research is necessary to analyse whether this is a natural fluctuation or a significant trend.

Many suicidal patients in our database had previously been in contact with mental health professionals, which is in line with an earlier study on reports of the Dutch Health Inspectorate. ${ }^{31}$ They must have been referred to mental healthcare by GPs previously for good reasons, for some patients possibly including suicidal ideation. Specialised mental healthcare therefore has been available and accessible for many patients who later on engaged in fatal and non-fatal suicidal behaviours. We observed that the rate of males under treatment of a mental health professional before the suicidal event decreased after the economic crisis. This might mean that in times of economic recession depression becomes less important as a risk factor to suicide compared to financial hardship.

\section{Limitations}

The data were collected in a subsample of 40 general practices participating in the Dutch NIVEL Primary Care Database. Although the sample is nationally representative by age, gender, regional distribution and population density, the sample is relatively small, consistent with the low incidence of suicide (attempts). Under-reporting of suicidal behaviour may have occurred in our study as cases were only counted after correct ICPC coding of suicidal behaviour (P77). In routine daily practice, some incorrect coding may occur. In addition, GPs were asked to record the questionnaire after a notification of suicidal behaviour. This might have influenced their answers, possibly inducing memory bias. ${ }^{32}$ GPs might be more susceptible to report noticing risk factors predicting the suicidal behaviour than was actually the case.

The retrospective analysis of GP records following suicide deaths and attempts is a useful means of establishing the ways in which mortality and morbidity from suicide could be prevented or addressed. However, the main limitation of this approach is the absence of a comparator group of patients who did not go on to attempt or complete suicide. Therefore, we cannot, for example, examine whether the percentage of suicidal patients who live alone is relatively high or low compared to other patients.

Also, we only have data on registered actual suicidal behaviour; we have no idea how the actions of the GP (treatment, medication, referral) effectively prevented 
suicidal behaviour in other cases. The decline in suicide rates and suicidal behaviour from 2003 to 2007 among men, and the continuous decline of suicidal behaviour among women over the past 30 years, could be the result of better assessment, treatment and referral by GPs. In $63 \%$ of the patients who died by suicide, GPs reported a history of depression. This remains an underestimation of the true prevalence of about $87 \%$ diagnosable depression in suicidal patients. ${ }^{33}$ Previous studies have shown that training GPs in the recognition of depression can influence the suicide rates. ${ }^{44}$

Despite several initiatives ${ }^{363536}$ to increase the assessment of suicide risk in depressed patients, the percentage of cases in which the GP report suicidal ideation as one of the four most important symptoms of depression has remained stable over the years. This does not mean that the GP did not discuss suicide ideation, but that GPs found other symptoms more important. Since we know that suicide ideation is an important predictor for future suicidal behaviour, GPs might be trained to learn about the predictive power of suicidal communication. ${ }^{37}$ Future studies should ask GP to routinely record suicidal ideation to give a more complete picture of how often suicidal ideation was discussed with depressed or suicidal patients.

In one of every four cases of patients who engaged in suicidal behaviour within 30 days (and who were questioned about this with hindsight knowledge of the actual suicidal behaviour), GPs identified suicidal ideation as an important concern during the last visit. In many other cases, the suicidal behaviour has come as a surprise. This may be related to the hesitation of suicidal patients to reveal their suicidal thoughts and plans, or that perhaps at that moment the patient did not have suicidal ideation at all, but developed suicidal plans days and weeks after the last visit.

This points towards the difficulty GPs face in responding to depressed patients when suicidal ideation is not overtly presented. The Dutch College of General Health Practitioners (NHG) reports the identification of suicidal ideation within depression as an important part of estimating the severity of the depression. ${ }^{38}$ Also, the NHG endorsed the Multidisciplinary Practice Guideline for the Assessment and Treatment of suicidal behaviour. At the same time, GPs generally do not have any formal training in suicide risk identification. ${ }^{39}$ Suicide prevention is not part of their systematic training in undergraduate or postgraduate education. Notwithstanding some local initiatives for postgraduate training, the majority of Dutch GPs did not follow systematic training in this respect. ${ }^{39}$

The Dutch rise in suicide rate was among the highest in Europe since the crisis. Only Greece showed a higher increase in suicide rate. However, it is good to realise that even in 2013, the Dutch suicide rate is low compared to surrounding countries such as Belgium and Germany. Also, to halt the rise, the ministry of Health has launched a national prevention strategy. Many gatekeepers such as teachers and bailiffs and professionals have been trained in the recognition of suicide ideation.
GPs and mental health nurses have had access to elearning and training since 2014. Future studies will give an insight into the effects of these interventions.

To sum up, we saw a rise in male suicidal behaviour while the female suicide behaviours gradually continued to decline. The rise in suicidal behaviour among middle-aged and older-aged men is alarming, and asks for new insights in male suicidal behaviour during an economic recession. A study combining cause of death statistics from the national statistics centre with the NIVEL primary care database could inform us on the different healthcare paths among individuals in the years before the actual suicidal behaviour. ${ }^{40}$ This new information on specific risk factors for male suicidal behaviour could help GPs to identify latent suicidal behaviour earlier and more accurately. For now, we advise GPs to be especially aware of middle-aged male patients who are (long term) unemployed, incapacitated or at risk of losing their job or income. Also, all reports of suicidal thoughts need to be taken seriously, even if those thoughts are not a dominant feature of the depression. In the near future, many more (older) people will be living alone. ${ }^{41}{ }^{42}$ This is a welldocumented risk factor for suicidal behaviour, especially for men,. ${ }^{43-45}$ Therefore, GPs should not forget to assess (change in) household composition when assessing risk for suicidal behaviour. Communities and municipalities may also concentrate on offering special social and sports programmes for these target groups.

In the Netherlands, since 2014, the GP has been given a much more central role in the assessment, treatment and referral of psychiatric patients. ${ }^{7}$ The Ministry of Health advocates the transition from specialised mental healthcare to primary care. More psychiatric patients should be treated by the GP and nurses with psychiatric training, so that care can be provided closer to home and at lower cost. Since the transition, stable chronic psychiatric patients have to be monitored within general practice, and no longer within specialised mental health care. These developments, in combination with the ongoing economic recession, are bound to influence the numbers of GP-reported suicides and suicide attempts, and forces the GPs and supporting teams to be more aware of suicidal behaviour. Recently, a multidisciplinary training programme focusing on the structural assessment of suicidal behaviour in specialised mental healthcare led to improved confidence regarding the assessment of suicidal behaviour among professionals, and a quicker recovery of suicidal thoughts among depressed suicidal patients. ${ }^{46}{ }^{47}$ We argue that a similar structured implementation programme in primary care might improve the recognition rate of suicide ideation within depressed patients.

\section{Twitter Follow Derek de Beurs at @derekdebeuurs}

Contributors DPdB did the analysis and drafted the manuscript. MH prepared the data for data analysis and checked the analysis. GAD has been responsible for the data collection for the past decade. All authors worked on earlier 
versions of the manuscript and contributed substantially to the text. All approve of the last version to be submitted.

Funding The NIVEL primary care databases are structurally funded by the Dutch Ministry of Health. No additional funding was obtained for the analyses of this article.

Competing interests None declared.

Provenance and peer review Not commissioned; externally peer reviewed.

Data sharing statement No additional data are available.

Open Access This is an Open Access article distributed in accordance with the Creative Commons Attribution Non Commercial (CC BY-NC 4.0) license, which permits others to distribute, remix, adapt, build upon this work noncommercially, and license their derivative works on different terms, provided the original work is properly cited and the use is non-commercial. See: http:// creativecommons.org/licenses/by-nc/4.0/

\section{REFERENCES}

1. Bostwick JM, Rackley S. Addressing suicidality in primary care settings. Current Psychiatry Rep 2012;14:353-9.

2. O'Connor RC. Towards an integrated motivational-volitional model of suicidal behaviour. In: O'Connor RC, Platt S, Gordon J, eds. International handbook of suicide prevention: research, policy and practice. West Sussex: John Wiley \& Sons, 2011:181-98.

3. Hegerl U, Rummel-Kluge C, Värnik A, et al. Alliances against Depression-a community based approach to target depression and to prevent suicidal behaviour. Neurosci Biobehav Rev 2013:37:2404-9.

4. Hegerl U, Mergl R, Havers I, et al. Sustainable effects on suicidality were found for the Nuremberg alliance against depression. Eur Arch Psychiatry Clin Neurosci 2010;260:401-6.

5. Luoma JB, Martin CE, Pearson JL. Contact with mental health and primary care providers before suicide: a review of the evidence. JAMA Psychiatry 2002;159:909-16.

6. Marquet R, Donker G. Praten over suïcidegedachten. Huisarts en Wetenschap 2009;52:267-7.

7. Nederlandse Zorgautoriteit. Advies Basis GGZ. Utrecht 2011. http:// www.nza.nl/104107/139830/465987/Advies Basis GGZ.pdf (accessed 18 Feb 2016)

8. Boffin N, Moreels S, Van Casteren V. Trends from the surveillance of suicidal behaviour by the Belgian Network of Sentinel General Practices over two decades: a retrospective observational study. BMJ Open 2015;5:e008584.

9. Reynders A, Kerkhof AJ, Molenberghs G, et al. Help-seeking, stigma and attitudes of people with and without a suicidal past. A comparison between a low and a high suicide rate country. $J$ Affect Disord 2015;178:5-11.

10. Statistics Netherlands (CBS). http://statline.cbs.nl/statweb/ (accessed 18 Feb 2016)

11. van Hemert AM, Kerkhof AFJM, de Keijser J, et al. Multidisciplinaire richtlijn voor diagnostiek en behandeling van suïcidaal gedrag. Utrecht: Nederlandse Vereniging voor Psychiatrie/Nederlands Intstituut voor Psychologen/Trimbos Instituut, 2012.

12. Joiner T. Why people die by suicide. MA: Harvard University Press, 2009.

13. Diekstra RF, van Egmond M. Suicide and attempted suicide in general practice, 1979-1986. Acta Psychiatr Scand 1989;79:268-75.

14. Barr B, Taylor-Robinson D, Scott-Samuel A, et al. Suicides associated with the 2008-10 economic recession in England: time trend analysis. BMJ 2012;345.

15. Gunnell D, Platt S, Hawton K. The economic crisis and suicide. BMJ 2009;338:b1891.

16. Pompili M, Vichi M, Innamorati $M$, et al. Suicide in Italy during a time of economic recession: some recent data related to age and gender based on a nationwide register study. Health Soc Care Community 2014;22:361-7.

17. Nordt C, Warnke I, Seifritz E, et al. Modelling suicide and unemployment: a longitudinal analysis covering 63 countries, 200011. Lancet Psychiatry 2015;2:239-45.

18. Qin P, Mortensen PB, Agerbo E, et al. Gender differences in risk factors for suicide in Denmark. Br J Psychiatry 2000;177:546-50.

19. Norström T, Grönqvist $H$. The great recession, unemployment and suicide. J Epidemol Community Health 2015;69:110-16.

20. Ahmad OB, Boschi-Pinto C, Lopez AD, et al. Age standardization of rates: a new WHO standard. Geneva: World Health Organization, 2001. http://www.who.int/healthinfo/paper31.pdf (accessed 10 Jan 2015).
21. Kim HJ, Fay MP, Feuer EJ, et al. Permutation tests for joinpoint regression with applications to cancer rates. Stat Med2000;19:335-51.

22. Mościcki EK. Gender differences in completed and attempted suicides. Ann Epidemiol 1994;4:152-8.

23. Milner A, Page A, Lamontagne A. Cause and effect in studies on unemployment, mental health and suicide: a meta-analytic and conceptual review. Psychol Med 2014;44:909-17.

24. O'Connor RC, Nock MK. The psychology of suicidal behaviour. Lancet Psychiatry 2014;1:73-85.

25. Williams JMG, Williams M. Cry of pain: understanding suicide and self-harm. London: Penguin Books, 1997.

26. Kerkhof A, van Spijker B. Worrying and rumination as proximal risk factors for suicidal behaviour. In: O'Connor RC, Platt S, Gordon J, eds. International handbook of suicide prevention. research, policy and practice. West Sussex: John Wiley \& Sons, 2011:199-209.

27. Cuijpers P, de Beurs DP, van Spijker BA, et al. The effects of psychotherapy for adult depression on suicidality and hopelessness: a systematic review and meta-analysis. J Affect Disord 2013;144:183-90.

28. Lundin A, Lundberg I, Allebeck P, et al. Unemployment and suicide in the Stockholm population: a register-based study on 771,068 men and women. Public health 2012;126:371-7.

29. Mäki N, Martikainen $P$. A register-based study on excess suicide mortality among unemployed men and women during different levels of unemployment in Finland. J Epidemol Community Health 2012;66:302-7.

30. Gemmill A, Falconi A, Karasek D, et al. Do macroeconomic contractions induce or 'harvest'suicides? A test of competing hypotheses. J Epidemol Community Health 2015;69:1071-6.

31. Huisman A, Robben P, Kerkhof AJ. An examination of the Dutch Health Care Inspectorate's supervision system for suicides of mental health care users. Psychiatr Serv 2009;60:80-5.

32. Arkes HR. The consequences of the hindsight bias in medical decision making. Curr Dir Psychol Sci 2013;22:356-60.

33. Cheng AT, Chen TH, Chen C-c, et al. Psychosocial and psychiatric risk factors for suicide. Case-control psychological autopsy study. Br J Psychiatry 2000;177:360-5.

34. Rutz W, Knorring vL, Wålinder J. Frequency of suicide on Gotland after systematic postgraduate education of general practitioners. Acta Psychiatr Scand 1989;80:151-4.

35. Marquet RL, Bartelds Al, Kerkhof AJ, et al. The epidemiology of suicide and attempted suicide in Dutch general practice 1983-2003. BMC Fam Pract 2005;6:45.

36. Egmond M. De beoordeling van suiciderisico door de huisarts [doctoral dissertation]. Leiden: 1988

37. Coryell W, Young EA. Clinical predictors of suicide in primary major depressive disorder. J Clin Psychiatry 2005;66:412-17.

38. Van Marwijk H, Grundmeijer H, Bijl D, et al. NHG-Standaard Depressieve stoornis (depressie). NHG-Standaarden Houten: Springer, 2009:521-37.

39. Bool M, Doeven M. Verminderen van suïcidaliteit: beleidsadvies: actualisering van het Advies inzake Suïcide, Gezondheidsraad 1986. Utrecht: Trimbos-Instituut, 2007.

40. Kerkhof AJFM, Sluijter A. Onderzoeksagenda Suicidepreventie. Den Haag: ZONMW, 2015. http://www.zonmw.nl/uploads/tx vipublicaties/ ZonMw_Onderzoeksagenda_Suicidepreventie_juni2015.pdf (accessed 18 Feb 2016).

41. Kinsella K, Velkoff V. Census bureau. An aging world: 2001. Washington DC: US Government Printing Office, 2001: series P95/ 01-1, 2011.

42. Tomassini C, Glaser K, Wolf DA, et al. Living arrangements among older people: an overview of trends in Europe and the USA Population Trends-London, 2004:24-35

43. Schneider B, Lukaschek K, Baumert J, et al. Living alone, obesity, and smoking increase risk for suicide independently of depressive mood findings from the population-based MONICA/KORA Augsburg cohort study. J Affec Disord 2014;152:416-21.

44. Almeida OP, Draper B, Snowdon J, et al. Factors associated with suicidal thoughts in a large community study of older adults. $\mathrm{Br} J$ Psychiatry 2012;201:466-72.

45. Middleton N, Whitley E, Frankel S, et al. Suicide risk in small areas in England and Wales, 1991-1993. Soc Psychiatry Psychiatr Epidemiol 2004;39:45-52.

46. de Beurs DP, de Groot MH, de Keijser J, et al. The effect of an e-learning supported Train-the-Trainer programme on implementation of suicide guidelines in mental health care. $J$ Affect Disord 2015;175:446-53.

47. De Beurs DP, De Groot MH, de Keijser J, et al. Evaluation of benefit to patients of training mental health professionals in suicide guidelines: cluster randomized trial. Br J Psychiatry 2015; Published Online First 17 Dec 2015. doi:10.1192/bjp.bp.114.156208 